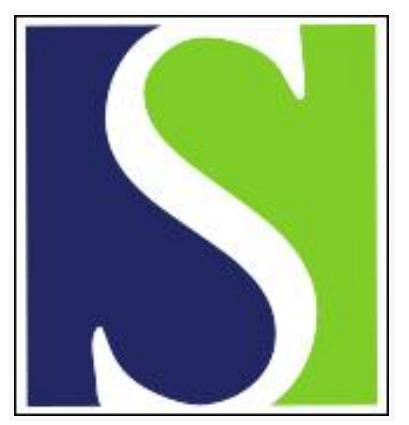

Scand J Work Environ Health 2003;29(2):106-116

https://doi.org/10.5271/sjweh.712

Issue date: Apr 2003

Effects of software programs stimulating regular breaks and exercises on work-related neck and upper-limb disorders

by van den Heuvel SG, de Looze MP, Hildebrandt VH, Thé KH

Affiliation: PO Box 718, 2130 AS, Hoofddorp, The Netherlands. S.vdHeuvel@arbeid.tno.nl

The following article refers to this text: 2010;36(1):25-33

Key terms: computer work; effect; exercise; microbreak; productivity; randomized controlled trial; regular break; rest break; sick leave; software program; work-related neck disorder; work-related upper-limb disorder

This article in PubMed: www.ncbi.nlm.nih.gov/pubmed/12718496

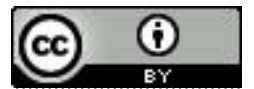




\title{
Effects of software programs stimulating regular breaks and exercises on work-related neck and upper-limb disorders
}

\author{
by Swenne G van den Heuvel, MA, ${ }^{1}$ Michiel P de Looze, PhD, ${ }^{1,2}$ Vincent H Hildebrandt, PhD, ${ }^{1,2}$ \\ Kiem H Thé, MSc ${ }^{1}$
}

\begin{abstract}
van den Heuvel SG, de Looze MP, Hildebrandt VH, Thé KH. Effects of software programs stimulating regular breaks and exercises on work-related neck and upper-limb disorders. Scand $J$ Work Environ Health 2003;29(2):106-116.

Objectives This study evaluated the effects on work-related neck and upper-limb disorders among computer workers stimulated (by a software program) to take regular breaks and perform physical exercises. Possible effects on sick leave and productivity were studied as well.

Methods A randomized controlled design was used with cluster randomization. Altogether 268 computer workers with complaints in the neck or an upper limb from 22 office locations were randomized into a control group, one intervention group stimulated to take extra breaks and one intervention group stimulated to perform exercises during the extra breaks during an 8-week period. Questionnaires were administered before and after the intervention, and questions were generated by the software during the intervention period. Computer usage was recorded online.

Results The data on self-reported recovery suggested a favorable effect; more subjects in the intervention groups than in the control group reported recovery (55\% versus 34\%) from their complaints and fewer reported deterioration (4\% versus 20\%). However, a comparison between the reported pre- and postintervention scores on the severity and frequency of the complaints showed no significant differences in the change among the three groups. No effects on sick leave were observed. The subjects in the intervention groups showed higher productivity.

Conclusions The use of a software program stimulating workers to take regular breaks contributes to perceived recovery from neck or upper-limb complaints. There seems to be no additional effects from performing physical exercises during these breaks.
\end{abstract}

Key terms computer work, microbreaks, productivity, randomized controlled trial, rest breaks, sick leave.

A rapidly increasing number of people are involved in computer work for increasing periods of time. Data from the European Foundation of Living and Working Conditions show that the percentage of workers who are involved in computer work "all the time" or "almost all the time" is $19 \%$ in the European Union (1). Other studies have shown that the daily amount of time performing computer work is positively related to the prevalence of neck and upper-limb disorders (2). Hence, a growing number of people in the European Union are at risk of neck and upper-limb disorders.

Personal, organizational, workplace, and task factors have been identified as contributors to musculoskeletal risk (3-5). In the literature, attention is drawn to strategies for reducing the intensity of physical load by redesigning the workstation. Indeed, workstation optimization, keyboard and mouse redesign, and the use of lower arm supports were found to be effective in reducing physical load and local discomfort (6-8). However, the effectiveness of these strategies in reducing neck and upper-limb disorders remains questionable. Particularly neck and shoulder disorders seem impervious to these workstation improvements (9). Since the intensity of the physical load is relatively low in computer work, it has been suggested that changes in the temporal pattern of the worktask (eg, extra rest breaks allowing for periods

1 TNO Work and Employment (TNO = The Netherlands Organization for Applied Scientific Research), Hoofddorp, The Netherlands.

2 Body@Work, Research Center Physical Activity, Work and Health TNO-VU, The Netherlands.

Correspondence to: Ms SG van den Heuvel, PO Box 718, 2130 AS, Hoofddorp, The Netherlands.

[E-mail: S.vdHeuvel@arbeid.tno.nl] 
of recovery from the monotonous load) may be more effective than strategies reducing load intensity.

Currently, software programs are available that stimulate computer workers to take frequent breaks during the day. A warning signal on the screen indicates the advisability of a break. The signal appears at specific intervals, which in some programs depend on the intensity of the work. Some programs also recommend the performance of light exercises during the breaks. The effectiveness of these programs in reducing the prevalence rates of neck and upper-limb disorders has not yet been evaluated. However, several findings reported in the literature support the effectiveness of these programs.

First, a cross-sectional study among 260 computer workers showed that those who had a limited opportunity to take rest breaks had more musculoskeletal complaints in the neck, shoulders, arms, and hands than others (3). Second, an experimental study among 42 dataentry operators showed that the implementation of additional breaks (4 times a day about 5 minutes) led to less local (short-term) discomfort in the upper extremities. In addition, the day-to-day increase in local discomfort during the week, which is present at the "normal" work-rest scheme, is eliminated by extra breaks (10). The favorable effect of extra breaks on musculoskeletal complaints or discomfort has been shown in other studies as well (11-13). Third, an experimental study showed that microbreaks of several seconds led to less local discomfort in the upper extremities among computer workers (14). Fourth, an experimental field study among 12 word processor operators showed that operators with active breaks reported less muscle discomfort than those with passive breaks (15). Finally, extra breaks did not lead to less productivity $(10,16,17)$. Sometimes even higher productivity was found (13).

The objective of this study was to evaluate the effects of a software program that stimulates extra breaks and exercises on the recovery from neck and upper-limb complaints among computer workers. In addition, effects on sick leave and productivity were studied.

\section{Subjects and methods}

\section{Design}

A randomized controlled trial was performed, including one control group and two intervention groups. Cluster randomization was used for office locations. In all the groups, the workplaces were ergonomically screened and adjusted if necessary. In the first intervention group a software program (an adjusted version of WorkPace, Niche Software Ltd., New Zealand) was installed that stimulated the workers to take frequent breaks. In the second intervention group, the workers were additionally stimulated by means of the software program to perform exercises during their regular breaks. The study was approved by the Medical Ethics Committee of The Netherlands Organization for Applied Scientific Research (TNO). Measurements were made 3 weeks before the intervention period and again after 3 months.

\section{Subjects}

Subjects were recruited from a large office organization (GAK Nederland) dealing with social security allowances. All employees (about 12000) were requested to answer a short questionnaire on work and health characteristics. They were asked if they were working at least 4 days a week in the office, were involved in computer work for at least 5 hours a day, had their own personal computer at work, had currently had complaints in the neck, shoulders, arms, wrists, hands, or fingers for at least 2 weeks, considered their complaints work-related, and were not under medical treatment for these complaints. They were asked to return the questionnaire only if they met the criteria. About 1700 employees returned the questionnaire, and about 1000 met the criteria for the study (figure 1). For each of the 22 locations, the first 20 employees who returned the questionnaire and met the criteria were invited to a final screening by the allied occupational health physician. The physician checked the aforementioned criteria and determined whether the complaints could be regarded as repetitive strain injuries according to the definition of the Health Council of The Netherlands (18).

The employees who needed treatment for their complaints, according to the judgment of the physician, were excluded, as were employees with other health problems (including medication intake) that may affect behavior at work. The age of the participants had to be between 18 and 50 years.

Not all the occupational health physicians had the time or opportunity to invite as many as 20 employees for screening. In addition, some employees did not pass the final screening. Eventually, this procedure resulted in the inclusion of 280 persons who received a questionnaire with an informed consent form. Altogether 268 returned the questionnaire and filled out the informed consent form. The 22 office locations were randomized into the control group, the first intervention group, and the second intervention group. A randomization procedure in a spreadsheet program was used that randomly assigned each location a figure between 1 and 3 .

The randomization assigned the employees in six locations to the control group ( $\mathrm{N}=90)$, those in eight locations to the intervention group that was stimulated to take breaks $(\mathrm{N}=97)$, and those in eight locations to the intervention group that was stimulated to take 


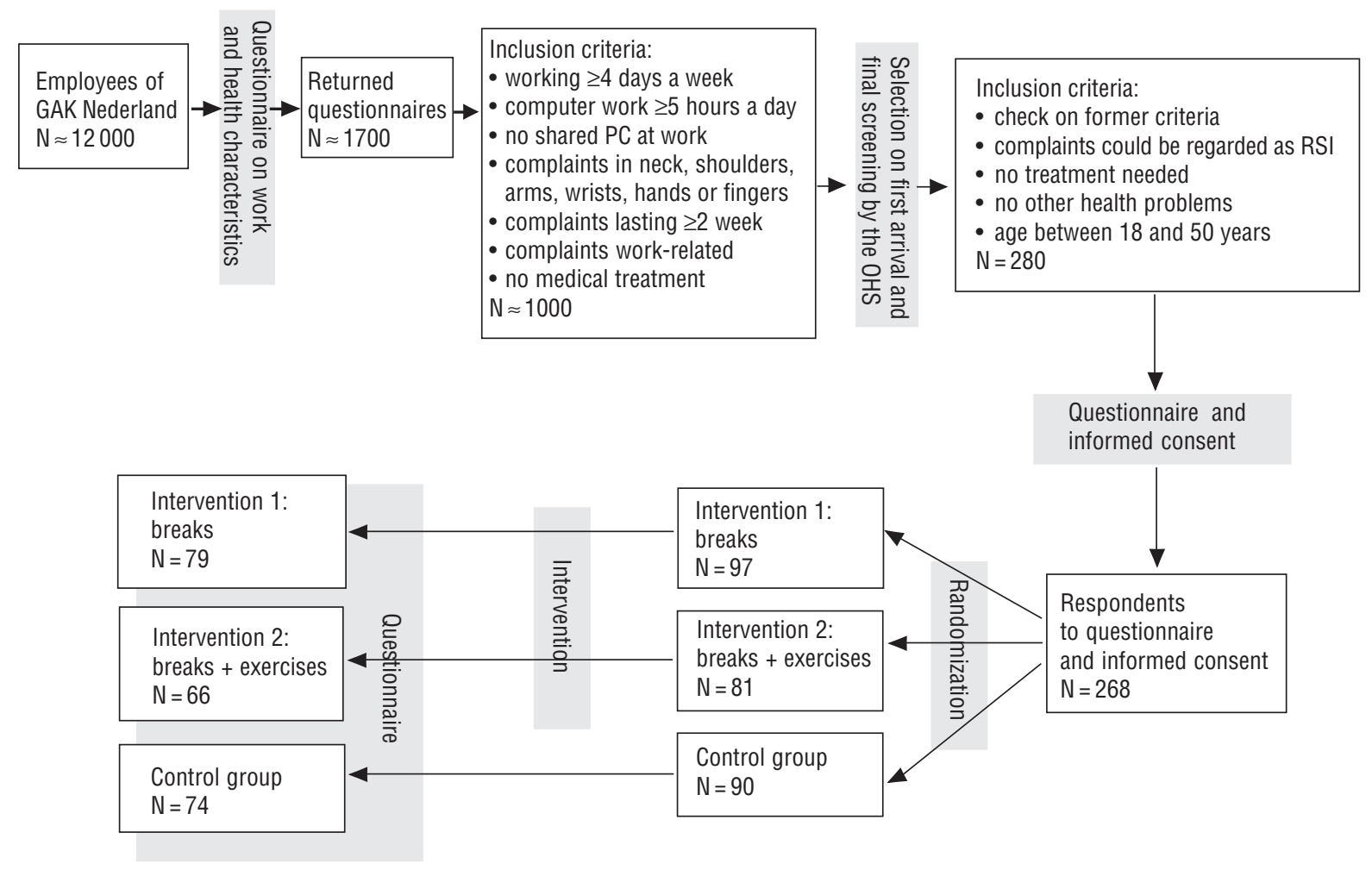

Figure 1. Participant flow. $(\mathrm{PC}=$ personal computer, $\mathrm{OHS}=$ occupational health service, $\mathrm{RSI}=$ repetitive strain injuries $)$

Table 1. Baseline complaint characteristics of the control and intervention groups.

\begin{tabular}{|c|c|c|c|}
\hline & \multirow[b]{2}{*}{$\begin{array}{l}\text { Control group a } \\
\quad(N=90)\end{array}$} & \multicolumn{2}{|c|}{ Intervention group } \\
\hline & & $\begin{array}{l}\text { Breaks }{ }^{b} \\
(\mathrm{~N}=97)\end{array}$ & $\begin{array}{c}\text { Breaks }+ \text { exercises }{ }^{c} \\
\quad(\mathrm{~N}=81)\end{array}$ \\
\hline \multicolumn{4}{|c|}{ Frequency complaints $^{d}$} \\
\hline Neck & 0.59 & 0.52 & 0.60 \\
\hline Shoulders & 0.58 & 0.52 & 0.55 \\
\hline Upper arms & 0.34 & 0.24 & 0.42 \\
\hline Elbows & 0.25 & 0.19 & 0.27 \\
\hline Forearms & 0.31 & 0.31 & 0.41 \\
\hline Wrists & 0.39 & 0.40 & 0.44 \\
\hline Hands or fingers & 0.39 & 0.39 & 0.42 \\
\hline \multicolumn{4}{|l|}{ Severity complaints ${ }^{\mathrm{e}}$} \\
\hline Neck & 4.64 & 4.20 & 4.57 \\
\hline Shoulders & 4.52 & 4.21 & 3.97 \\
\hline Upper arms & 2.85 & 2.42 & 2.96 \\
\hline Elbows & 2.37 & 1.90 & 2.29 \\
\hline Forearms & 2.70 & 2.86 & 3.14 \\
\hline Wrists & 3.11 & 3.52 & 3.29 \\
\hline Hands or fingers & 3.06 & 3.45 & 3.24 \\
\hline
\end{tabular}

a Group $43 \%$ men and $57 \%$ women with a mean age of 37 years.

${ }^{b}$ Group $46 \%$ men and $54 \%$ women with a mean age of 39 years.

c Group $66 \%$ men and $34 \%$ women with a mean age of 42 years.

${ }^{d}$ The participants could choose between the following four categories: $0=$ no pain, $0.33=1$ day, $0.67=2-3$ days, $1=4-7$ days in the previous week.

${ }^{e}$ The participants could indicate the severity of their pain in the previous week on a scale from 1 (no complaints) to 10 (severe complaints). both breaks and exercises $(\mathrm{N}=81)$. The baseline characteristics of the control and intervention groups are presented in table 1.

After the intervention period the participants had to fill out a second questionnaire including their name to match the data before and after the intervention. Seven questionnaires were not traceable to their senders. Altogether 219 subjects returned the second questionnaire with their name on it: 74 in the control group, 79 in the intervention group with breaks, and 66 in the intervention group with breaks and exercises. The reasons for not returning the questionnaire (or returning it anonymously) were unknown for 39 subjects, 7 subjects did not return the questionnaire because no software was installed, 2 subjects changed work, and 1 subject was on long-term sick leave (figure 1).

To check whether the participants performed the exercises, we had to rely on their own reports. In the intervention group that was invited to perform exercises, the software generated questions after each rest break on how they spent their rest breaks and whether they performed the exercises. In the general questionnaire after the intervention period they were also asked whether they performed the exercises. According to the answers in the general questionnaire, $74 \%$ of the 
participants performed the exercises most of the time, $18 \%$ now and then, and $8 \%$ rarely or never. According to the questions posed after each rest break, all the exercises were performed in $78 \%$ of all rest breaks; the exercises were ignored completely in $9 \%$ of the rest breaks, and in $13 \%$ of the rest breaks some of the exercises were performed, but not all of them. There were large individual differences: $3 \%$ of the participants did none of the exercises, while $17 \%$ did them all during the entire intervention period, during each prompted break.

\section{Intervention}

The duration of the intervention period was 8 weeks. Before the intervention, the position of the seat, table height, position of the monitor, keyboard, and mouse was checked in all the groups and, if necessary, individually adjusted according to current ergonomic standards, recommended by the Dutch Labor Inspectorate (19). In $30 \%$ of the cases, an adjustment was made. There was no difference between the three groups in the percentage of adjustments. In addition, all the participants received a small attractive booklet with general information on neck and upper-limb disorders, as well as a neck and upper-limb disorder risk test.

In the first intervention group the participants were prompted by a signal on the screen to take a rest break of 5 minutes after each period of continuous computer usage of 35 minutes, and a microbreak of 7 seconds after each period of continuous computer usage of $5 \mathrm{~min}$ utes. This signal was not given when the periods were already interrupted by a "natural" rest break or microbreak of the same duration as long or longer than the prompted breaks. Rest breaks could be postponed once for 15 minutes. During the breaks the computer was blocked. After the break the computer was automatically activated. Microbreaks could not be ignored. In this way the participants were not able to evade the break scheme.

In the second intervention group, the same scheme of rest breaks and microbreaks was applied. In addition, the workers in this group were stimulated to perform four physical exercises (lasting 45 seconds each) at the start of each rest break. The exercises were presented on the screen (see figure 2). They were relatively easy and most of them could be performed while seated. After 45 seconds, the "done" button needed to be pressed to go to the next exercise. During the remaining period of the rest break the computer was blocked, and the subjects were free to do something else.

\section{Measurements}

At baseline, all the subjects completed a questionnaire on complaints (location, frequency and severity), on their sick leave due to these complaints, on personal factors (eg, gender, age, leisure-time activities), and on work characteristics (eg, tasks, workhours, psychosocial work characteristics). Psychosocial work characteristics were measured by means of the Job Content Questionnaire (20). Furthermore, participants were asked if they could agree on some propositions with regard to their expectations of the break and exercise stimulating software. Positive and negative expectations were listed in the questionnaire.

After the intervention period, all the subjects completed a similar questionnaire. Questions were added concerning the "after usage" opinion of the software, the recommended breaks and exercises (in the intervention groups), and the perceived recovery of the complaints (in all the groups).

In all the groups, software was installed that measured the computer usage of the participants. The software generated questionnaires as well. In the intervention groups, after each rest break, the participants were asked how they spent their rest breaks. In an automatically activated pop-up menu they could choose between one or more of the following activities: making telephone calls, reading or writing, waiting until the computer became active again, doing nonwork activities like drinking coffee or chatting with colleagues, doing work activities like collecting mail or walking to printer. The participants in the second intervention group who were stimulated to do exercises were also asked if they actually performed the exercises.

\section{Outcomes}

The main outcome was the perceived overall recovery from complaints after the 8-week intervention period, measured with a questionnaire on a 7-point scale, where $1=$ complete recovery, $2=$ much improvement, $3=$ little improvement, $4=$ no change, $5=$ slight deterioration, $6=$ much deterioration, $7=$ worse than ever before.

One of the secondary outcomes concerned the frequency and severity of complaints. The frequency of

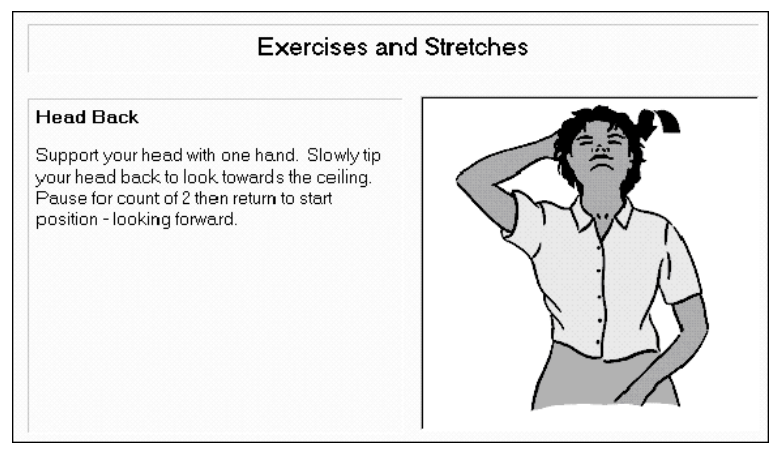

Figure 2. One of the exercises presented on the screen during a prompted rest break. 
complaints was measured by asking the participants how often they felt discomfort or pain in their neck, shoulders, upper arms, elbows, forearms, wrists, and hands or fingers during the previous week. They could choose between the categories "no pain", "1 day", "2-3 days", or "4-7 days". The severity of the complaints was measured by asking the participants to rate it on a scale from 1 to 10 .

In addition self-reported sick leave in the data from the questionnaires formed a secondary outcome. In both questionnaires, the participants were asked if they had been on sick leave as a result of their complaints during the last 3 months. They were also asked to estimate the number of days of their sick leave.

For productivity, a third secondary outcome, the mean number of key strokes a day, was computed during the intervention period. For the error rate, the mean number of key strokes of the backspace key and the delete key was computed. With these data, the accuracy rate was computed according to the following criteria equation:

accuracy rate $=1-($ number of backspace + delete key strokes) / total number of key strokes.

A power analysis indicated that at least 80 workers per arm were needed to detect a difference of $20 \%$ between the groups with respect to the main outcome (alpha 0.05 , beta 0.20$)$.

\section{Analysis}

Although group randomization was used, the analyses were executed in the same manner as an individually randomized trial. According to the authors, this can be considered a sound procedure as the population was highly homogeneous. The office locations shared exactly the same tasks, work methods, procedures, and the like and were under the management of the same head office.

To analyze the differences among the three groups with respect to the main outcome, a crosstab procedure was used. Adjusted standardized residuals were calculated to determine any significant differences (21). The frequency and severity scores were analyzed for the separate body regions. To summarize the effects on musculoskeletal complaints, we grouped the body regions into "neck and shoulders" and "arms, elbows, wrists and hands or fingers". Both the average score and the highest score across body regions were analyzed. To determine whether the frequency and severity of the complaints for the separate and the grouped body regions had changed during the intervention period, we used a paired T-test. An analysis of variance (ANOVA) was used to examine whether the changes in the intervention groups differed significantly from the changes in the control group. Because the intervention groups and the control group differed in gender and age, the ANOVA was repeated with adjustment for these variables and the adjusted means were computed. To adjust the analysis by self-reported recovery, the ANOVA procedure was used as well.

Interaction terms were studied for the variables "expected effectiveness of the software" and "job demands". To avoid collinearity, we centered the interaction terms by first subtracting their means from the variables before multiplying them (22). To determine whether the interaction terms were significant, regression analyses were performed with models consisting of a variable concerning the group, the variable under study, and the centered interaction term of both variables. The variables of the complaints in the grouped body regions and self-reported recovery served as the dependent variables. In these analyses the intervention groups were treated as one group.

To determine whether sick leave due to neck or upper-limb disorders had changed during the intervention period, a paired T-test was used. An ANOVA was used to study whether the changes in sick leave in the intervention groups differed significantly from the changes in the control group.

An ANOVA was used to study whether the intervention groups differed significantly from the control group with respect to productivity. Because the number of key strokes and the accuracy in typing was strongly associated with gender, age and level of education and because the control group and intervention groups differed concerning these variables, the results were adjusted for gender, age, and education level.

\section{Results}

\section{Perceived recovery}

Figure 3 gives the self-reported recovery from complaints as obtained directly after the period of intervention. Compared with the controls, the subjects in the intervention groups more frequently reported recovery from their complaints, while they less frequently reported deterioration. No difference was observed between the intervention groups.

\section{Musculoskeletal complaints}

In all the groups, the frequency and severity of most of the complaints decreased during the intervention period. The severity of complaints concerning the neck, shoulder, upper arm, forearm, wrist, and hands or fingers and the frequency of neck and shoulder complaints decreased; only the frequency of complaints concerning the elbow, wrist, and hands or fingers increased. The 
changes in the frequency and severity of complaints in the intervention groups did not significantly differ from those in the control group (results not shown).

Table 2 shows the changes in the frequency and severity of the complaints for the grouped body regions, adjusted for gender and age. "Highest" refers to the maximum score for frequency and severity in these regions, respectively, and "Mean" refers to the mean score of all complaints for these regions. The means for selfreported recovery are presented as well. No statistically significant differences in the change of complaints were found between the control group and the intervention groups. After adjustment for gender and age, self-reported recovery was still significantly higher in the intervention groups.

\section{Sick leave}

Only a small number of participants was not able to continue working as a result of their complaints, both before and after the intervention. This finding was not surprising because persons with severe complaints, needing medical treatment, were excluded from the study. Before the intervention $8.7 \%$ had had to go on sick leave due to neck or upper-limb disorders in the previous 4 months; during the intervention period the corresponding rate was only $5 \%$. Table 3 shows the sick leave of the control group and the intervention groups. There were no statistically significant differences between the groups.

\section{Productivity}

Table 4 presents the differences between the control group and the intervention groups in key strokes and accuracy rate. This table shows that productivity, expressed as the number of key strokes, was statistically significantly higher in the intervention group with

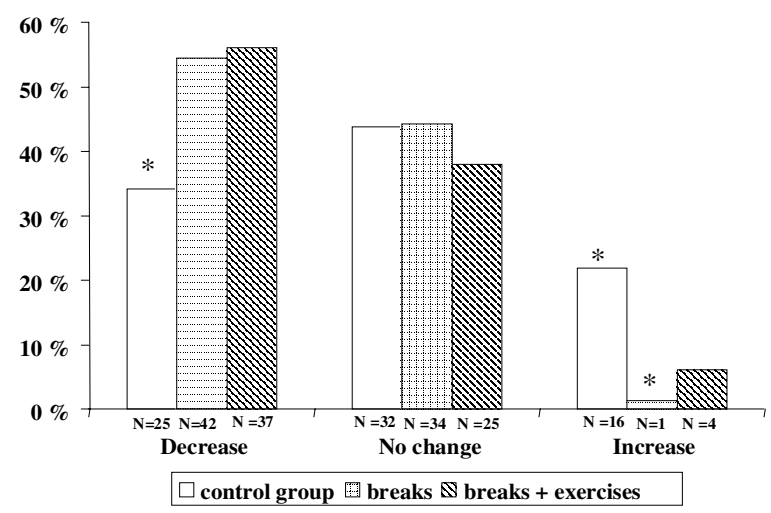

* Indicates a significant deviation from the expected value based on the value of the standard adjusted residual in this cell $(\leq 2$ or $>2)$.

Figure 3. Self-reported change in complaints.

Table 2. Scores of the change in frequency and severity of the complaints and their $95 \%$ confidence intervals (95\% $\mathrm{Cl}$ ), adjusted for gender and age (a negative score indicates a decrease in frequency or severity).

\begin{tabular}{|c|c|c|c|c|c|c|}
\hline & & & \multicolumn{4}{|c|}{ Intervention group } \\
\hline & \multicolumn{2}{|c|}{ Control group } & \multicolumn{2}{|c|}{ Breaks } & \multicolumn{2}{|c|}{ Breaks + exercises } \\
\hline & Change & $95 \% \mathrm{Cl}$ & Change & $95 \% \mathrm{Cl}$ & Change & $95 \% \mathrm{Cl}$ \\
\hline \multicolumn{7}{|l|}{ Frequency score ${ }^{a}$} \\
\hline Highest for neck and shoulders & 0.06 & $-0.15-0.03$ & 0.06 & $-0.15-0.03$ & 0.09 & $-0.19-0.01$ \\
\hline & -0.09 & $-0.17--0.02$ & -0.02 & $-0.10-0.05$ & -0.10 & $-0.18--0.02$ \\
\hline $\begin{array}{l}\text { Highest for arms, elbows, wrists, } \\
\text { hands or fingers }\end{array}$ & -0.05 & $-0.15-0.04$ & 0.00 & $-0.09-0.09$ & 0.01 & $-0.09-0.11$ \\
\hline $\begin{array}{l}\text { Mean for arms, elbows, wrists, } \\
\text { hands or fingers }\end{array}$ & 0.03 & $-0.03-0.09$ & 0.09 & $0.03-0.15$ & 0.03 & $-0.03-0.10$ \\
\hline Highest for all body regions & -0.15 & $-0.21--0.08$ & -0.08 & $-0.14--0.01$ & -0.04 & $-0.12-0.03$ \\
\hline Mean for all body regions & -0.01 & $-0.06-0.05$ & 0.05 & $0.00-0.11$ & -0.01 & $-0.06-0.05$ \\
\hline \multicolumn{7}{|l|}{ Severity score ${ }^{b}$} \\
\hline Highest for neck and shoulders & -1.7 & $-2.3--1.1$ & -1.5 & $-2.1--0.9$ & -1.8 & $-2.5--1.1$ \\
\hline Mean for neck and shoulders & -1.5 & $-2.1--1.0$ & -1.2 & $-1.7--0.6$ & -1.6 & $-2.2--1.0$ \\
\hline $\begin{array}{l}\text { Highest for arms, elbows, wrists, } \\
\text { hands or fingers }\end{array}$ & -1.4 & $-2.0--0.8$ & -1.5 & $-2.1--0.9$ & -1.1 & $-1.7--0.4$ \\
\hline $\begin{array}{l}\text { Mean for arms, elbows, wrists, } \\
\text { hands or fingers }\end{array}$ & -0.6 & $-0.9--0.2$ & -0.3 & $-0.7-0.0$ & -0.4 & $-0.8-0.0$ \\
\hline Highest for all body regions & -2.1 & $-2.7--1.5$ & -2.1 & $-2.7--1.6$ & -2.0 & $-2.6--1.4$ \\
\hline Mean for all body regions & -0.9 & $-1.2--0.5$ & -0.6 & $-0.9--0.3$ & -0.7 & $-1.1--0.4$ \\
\hline Self-reported change in complaints ${ }^{c}$ & 3.7 & $3.5-4.0$ & $3.3^{d}$ & $3.0-3.5$ & $3.3^{d}$ & $3.0-3.6$ \\
\hline
\end{tabular}

${ }^{a} \mathrm{~N}=70$ for the control group, 75 for the break only intervention group, and 64 for the break and exercise intervention group.

${ }^{b} \mathrm{~N}=68$ for the control group, 74 for the break only intervention group, and 63 for the break and exercise intervention group.

${ }^{c} \mathrm{~N}=71$ for the control group, 76 for the break only intervention group, and 65 for the break and exercise intervention group.

d Significantly $(P<0.05 \%)$ lower value than that of the control group according to the contrast results of the analysis of variance. 
Table 3. Sick leave due to neck or upper-limb disorders, before and after the intervention.

\begin{tabular}{|c|c|c|c|}
\hline \multirow[b]{2}{*}{ Sick leave } & \multirow[b]{2}{*}{$\begin{array}{l}\text { Control group } \\
(\mathrm{N}=74)\end{array}$} & \multicolumn{2}{|c|}{ Intervention group } \\
\hline & & $\begin{array}{l}\text { Breaks } \\
(\mathrm{N}=79)\end{array}$ & $\begin{array}{c}\text { Breaks + exercises } \\
\quad(\mathrm{N}=65)\end{array}$ \\
\hline & $(\%)$ & $(\%)$ & $(\%)$ \\
\hline Before intervention & 9.5 & 6.3 & 10.8 \\
\hline After intervention & 5.4 & 3.8 & 6.2 \\
\hline Change & -4.1 & -2.5 & -4.6 \\
\hline
\end{tabular}

Table 4. Differences in key strokes, correction key strokes, and accuracy rate between the control group and the intervention groups, adjusted for gender, age and level of education, during the intervention period.

\begin{tabular}{lccc}
\hline & & \multicolumn{2}{c}{ Intervention group } \\
\cline { 3 - 4 } & $\begin{array}{c}\text { Control group } \\
(\mathrm{N}=75)\end{array}$ & $\begin{array}{c}\text { Breaks } \\
(\mathrm{N}=89)\end{array}$ & $\begin{array}{c}\text { Breaks + exercises } \\
(\mathrm{N}=69)\end{array}$ \\
\cline { 2 - 4 } & 5351 & $6460^{\mathrm{a}}$ & 6034 \\
$\begin{array}{l}\text { Mean daily number of } \\
\text { key strokes }\end{array}$ & 199 & 263 & 252 \\
$\begin{array}{l}\text { Mean daily number of } \\
\text { backspace key strokes } \\
\begin{array}{l}\text { Mean daily number of } \\
\text { delete key strokes }\end{array}\end{array}$ & 215 & $71^{\mathrm{b}}$ & $72^{\mathrm{b}}$ \\
$\begin{array}{l}\text { Accuracy rate } \\
\mathrm{c}\end{array}$ & 93 & $95^{\mathrm{a}}$ & $95^{\mathrm{a}}$ \\
\hline
\end{tabular}

a Significantly $(P<0.05)$ higher value than that of the control group according to the contrast results of the analysis of variance.

${ }^{b}$ Significantly $(P<0.05)$ lower value than that of the control group ac-

cording to the contrast results of the analysis of variance.

c 1 - (backspace + delete) / total key strokes.

breaks and no exercises than in the control group. The accuracy rate in both intervention groups was higher than in the control group. The most striking difference between the groups was the number of delete key strokes, which was much higher in the control group than in the intervention groups.

\section{Interaction effects}

The regression analyses produced several significant interaction terms. Most of them concerned the variable "expectations of the software at baseline", the sum of the positive expectations agreed upon. Significant interaction terms were found for this variable, with most variables concerning the frequency of complaints (strongest effect for highest frequency of neck and shoulders) and self-reported change as the dependent variable. The results indicate that, in the intervention groups, positive expectations of the software were associated with more perceived recovery and a decrease in complaints. In the control group the finding was the reverse in that positive expectations were associated with less perceived recovery and an increase in complaints.

Another significant interaction term with self-reported change as the dependent variable was job demands.
The results indicate that there was no association between job demands and perceived recovery in the intervention groups, whereas in the control group high job demands were associated with more perceived recovery.

\section{Expectations and experiences}

Nearly all the subjects were completely unfamiliar with break-stimulating software. Only four subjects had used such a program in the past. Most of the subjects (65\%) did not expect the software without exercises to help reduce their complaints. With respect to the software with exercises, the expectations were more positive, as $78 \%$ of the subjects expected a positive effect on their complaints. Another positive expectation mentioned in the questionnaire concerned "more relaxation", and it was agreed on by $43 \%$ of the subjects. Negative expectations mentioned in the questionnaire and agreed on by more than $20 \%$ of the subjects were "loss of productivity" (33\%) and "embarrassment to perform exercises in the presence of colleagues" $(25 \%)$.

After the intervention period, the opinions of the subjects in the intervention groups were rather positive, as can be seen in table 5. In the experimental group that used the software without the exercises, $56 \%$ was satisfied to very satisfied, while $9 \%$ was dissatisfied to very dissatisfied. In the group with exercises, $65 \%$ of the subjects was satisfied to very satisfied, and only $5 \%$ was dissatisfied. Of all the users, $90 \%$ would recommend other computer workers with neck or upper-limb disorders to use the software. Table 5 also shows that agreement on the positive propositions concerning the software was much larger than concerning the negative propositions.

There were also some impeding factors for using the program. Table 6 shows the percentages of subjects who judged the factors mentioned as important or very important. The factors judged to be important or very important by more than $20 \%$ are "doing sufficient other things to reduce my complaints" and "no connection assumed between complaints and program". In the intervention group with exercises the loss of productivity was also judged to be an important impeding factor by more than $20 \%$. The impeding factors for performing the exercises were not often judged to be important.

\section{Discussion}

\section{Complaints}

The results on the effects of the software program seem to contradict each other. The comparison of the pre- versus postintervention scores of severity and frequency did not reveal any differences between the 
Table 5. Satisfaction with the program and agreement with the positive and negative propositions mentioned in the questionnaire.

\begin{tabular}{|c|c|c|c|c|}
\hline & \multicolumn{4}{|c|}{ Intervention group } \\
\hline & \multicolumn{2}{|c|}{ Breaks } & \multicolumn{2}{|c|}{ Breaks + exercises } \\
\hline & $\mathrm{N}$ & $\%$ & N & $\%$ \\
\hline \multicolumn{5}{|l|}{ Satisfaction with the program } \\
\hline Satisfied to very satisfied & 44 & 56 & 42 & 65 \\
\hline Not satisfied but not dissatisfied & 27 & 35 & 20 & 31 \\
\hline Dissatisfied to very dissatisfied & 7 & 9 & 3 & 5 \\
\hline Would recommend persons with initial complaints to use the software & 68 & 90 & 58 & 91 \\
\hline \multicolumn{5}{|l|}{ Agree or strongly agree with the following positive propositions } \\
\hline The program caused more relaxation & 36 & 46 & 36 & 55 \\
\hline You have to get used to it; then it is fine and it will have an effect & 37 & 48 & 39 & 61 \\
\hline The program is irritating, but it will have an effect & 23 & 30 & 19 & 29 \\
\hline After this study I want to continue using the program & 44 & 56 & 44 & 70 \\
\hline After this study I want to continue using the program and performing the exercises & & & 41 & 64 \\
\hline \multicolumn{5}{|l|}{ Negative propositions } \\
\hline As a result of the extra breaks, I had problems finishing my work & 5 & 6 & 9 & 14 \\
\hline Colleagues think I overreact by working with this software & 3 & 4 & 8 & 12 \\
\hline You have to get used to it; then it is fine but it has no effect & 18 & 23 & 10 & 16 \\
\hline The program is irritating, and it has no effect & 10 & 13 & 6 & 10 \\
\hline
\end{tabular}

control and intervention groups, whereas the results concerning (postintervention) perceived recovery revealed a favorable effect for the stimulation of regular breaks.

This favorable effect may have been caused by the presence of the intervention only, known as intervention bias. The software program may have placated people merely because their complaints were paid attention to. They were able to express this positive feeling when they were asked to indicate recovery from their complaints. Asking them to quantify the level of their complaints (instead of the change) did not offer the opportunity to react positively, as most people would not remember their baseline scores when filling in the postintervention scores.

However, this result could also be due to a favorable and meaningful effect of the software program in that it could have initiated a process of consciousness that possibly led to more favorable behavior (eg, work postures, muscle relaxation and extra breaks) and obviously a more positive attitude towards one's complaints. Possibly, the pain and discomfort had yet not diminished greatly, but the subjects expected that they could deal with it in such a manner that it would diminish further in the future.

Another factor that could have influenced the results is that a reduction of complaints was observed in all the groups. The overall decrease in complaints may have been caused either by the workplace adjustments or the information booklet provided in all the groups. Furthermore, when a population of subjects has complaints at the start of the intervention, the phenomenon "regression to the mean" is likely to occur. Be
Table 6. Impeding factors for using the program, mentioned in the questionnaire, as judged to be important or very important by the subjects.

\begin{tabular}{|c|c|c|c|c|}
\hline & \multicolumn{4}{|c|}{ Intervention group } \\
\hline & \multicolumn{2}{|c|}{ Breaks } & \multicolumn{2}{|c|}{$\begin{array}{l}\text { Breaks }+ \\
\text { exercises }\end{array}$} \\
\hline & $\mathrm{N}$ & $\%$ & N & $\%$ \\
\hline \multicolumn{5}{|l|}{$\begin{array}{l}\text { Impeding factors for using } \\
\text { the program }\end{array}$} \\
\hline No time for this & 10 & 13 & 11 & 18 \\
\hline $\begin{array}{l}\text { Doing sufficient other things to } \\
\text { reduce my complaints }\end{array}$ & 21 & 27 & 14 & 23 \\
\hline $\begin{array}{l}\text { My supervisor does not think this } \\
\text { is a solution }\end{array}$ & 5 & 7 & 1 & 2 \\
\hline $\begin{array}{l}\text { My colleagues do not want to } \\
\text { share in these activities }\end{array}$ & 5 & 7 & 6 & 10 \\
\hline $\begin{array}{l}\text { My productivity will suffer } \\
\text { with this program }\end{array}$ & 11 & 15 & 14 & 22 \\
\hline $\begin{array}{l}\text { My complaints do not have } \\
\text { anything to do with this }\end{array}$ & 18 & 24 & 11 & 18 \\
\hline \multicolumn{5}{|l|}{$\begin{array}{l}\text { Impeding factors for performing } \\
\text { the exercises }\end{array}$} \\
\hline I do not understand most of them & . & . & 8 & 13 \\
\hline It hurts too much & . & . & 8 & 14 \\
\hline I do not have the energy & . & . & 6 & 10 \\
\hline My colleagues would laugh at me & . & . & 2 & 3 \\
\hline I would feel embarrassed & . & . & 6 & 10 \\
\hline $\begin{array}{l}\text { There are better ways to spend } \\
\text { my time }\end{array}$ & $\cdot$ & . & 10 & 17 \\
\hline I do not feel like doing it & . & . & 5 & 9 \\
\hline $\begin{array}{l}\text { Exercises do not have any effect } \\
\text { on me }\end{array}$ & . & . & 5 & 9 \\
\hline
\end{tabular}

that as it may, it is obviously harder to determine favorable effects of software when the level of complaints also diminishes in the control group. 
Finally, a period of three months may not have been long enough to show the effects on the complaints. It would be important to assess the long-term effects of the software and evaluate whether the high perceived recovery found in the intervention groups persists over a longer follow-up period.

\section{Productivity}

When people take more breaks, it can be expected that the productivity of these people will decrease, as their worktime is shorter. However, the results of this study, and comparable results from other studies $(10,13,16$, 17), suggest that this assumption appears to be a misunderstanding, as no negative effects on productivity were found.

As no data on keystroke usage were available for the period before the intervention, the results in this study remain open to question. Although the results were adjusted for the most obvious factors, the differences in productivity between the groups could be attributed to already existing differences before the intervention period. Therefore, further study is needed with measurements of productivity before the intervention.

\section{Break scheme and exercises}

In the standard version of the software program used, a scheme was recommended of a 10-minute rest break after each period of continuous computer usage of $20 \mathrm{~min}$ utes when people had initial complaints. In this study a less stringent break scheme was applied with microbreaks of 7 seconds each 5 minutes and rest breaks of 5 minutes each 35 minutes. The reason for not using a more stringent break scheme was that the subjects had limited possibilities for ignoring the breaks in the adjusted version of the program that was used for the study. A more stringent scheme could seriously disrupt the normal work activities and reduce the willingness of subjects to participate in the study.

Possibly a scheme including more frequent or longer breaks would have led to different results. However, there is no support for such a stringent scheme in the literature. Favorable effects on discomfort or complaints have been found for rest breaks of 10 minutes after every hour of work (11), supplementary rest breaks of 5 minutes during each hour which otherwise did not contain a break (10), and microbreaks of 30 seconds taken at 20-minute intervals. However, no studies have been found concerning subjects with initial complaints exclusively. Additional studies are needed to determine the effects of more stringent schemes on complaints and to determine the compliance of computer workers with these schemes.
It is noteworthy that no favorable effect of additional exercises was observed with respect to the complaints of the subjects in our study, whereas, in several studies, the potential effect of active rest breaks has been demonstrated $(15,16)$ and the participants themselves expected such an additional effect as well. However, these studies did not concern the decrease in complaints, but other matters instead, such as productivity, performance, and perceived discomfort. Furthermore, the participants in the intervention group without exercises spent their breaks more often active (walking around) than inactive (waiting, reading or using the phone). It is also possible that natural breaks, not prompted by the software, were spent active as well, but we do not have information on this issue.

\section{Study population}

As the study population consisted of people with complaints in the neck or upper limbs, it was not possible to determine the preventive effect of the software on a healthy population (ie, the extent to which it can prevent the occurrence of neck and upper-limb disorders among healthy computer workers). The effectiveness of the software program depends on the willingness of people to use it. Possibly the willingness of healthy people to work with a break-stimulating software program is much lower than that of people with neck and upperlimb disorders. This factor would disrupt the preventive effect of the software.

The low response in the initial screening may have resulted in selection bias. Unfortunately no data on nonrespondents were available. However, it seems likely that workers without complaints, as well as workers who were not willing to use the software, did respond less. This occurrence may explain, to some extent, the very high satisfaction figures found for the participants with respect to the software used.

\section{Interaction effects}

The interaction effects indicated that the computer workers with positive expectations of the software profited more from the software. An explanation could be that these workers already suspected that their complaints were due to their attitudes concerning computer usage, whereas the workers who did not hold these expectations contributed their complaints to other sources. Another explanation could be that workers with few positive expectations of the software were irritated using it. This irritation could cause some form of stress that could influence their complaints. In the control group the knowledge that they did not have the opportunity to use the software could have irritated the computer workers 
with positive expectations, which could have had adverse effects on their complaints in the same manner.

The interaction effect concerning job demands is more difficult to interpret. It was expected that workers with relatively high job demands may profit less from the software if they are not able, or not willing, to follow the break scheme. However, there was no association between job demands and perceived recovery in the intervention groups of our study. It is not clear why job demands were associated with more perceived recovery in the control group.

\section{Randomization procedure}

The analyses were based on the assumption that the office locations were highly comparable, and, therefore, no correction was needed for the use of group randomization. Since only a few computer workers from every location were included in the study population, it would have made no sense to determine the variance between the office locations as opposed to the variance between the workers. If the first variance were considerably higher, it could have led to an overestimation of the statistical significance. However, for reasons mentioned earlier, we do not consider this possibility to be likely.

\section{Concluding remarks}

Although this study showed no effect of the software on the frequency and severity of complaints, it was found that computer workers with complaints in the neck or upper limbs who use break-stimulating software perceive more recovery from their complaints. An extra benefit of exercises was not observed. No effects were found on sick leave. Productivity expressed as the number of key strokes was higher in the intervention groups. The workers were satisfied with the software, and most of them would advise other computer workers with initial complaints to use it. The workers who had positive expectations of the software before the intervention seemed to profit more from the software than those who did not have these positive expectations.

\section{Acknowledgments}

We would like to thank all the office workers of GAK Nederland who took part in this study. GAK Nederland is also acknowledged for all its support and for providing all the facilities with which to perform this study. We also thank ErgoDirect en Niche Software, Ltd, for providing a special version of the WorkPace program.

The study was funded by ZorgOnderzoek Nederland.

\section{References}

1. Andries F, Smulders PGW, Dhondt S. The use of computers among the workers in the European Union and its impact on the quality of work. Behav Inf Technol. In press.

2. Punnet L, Bergqvist U. VDU work and upper extremity musculoskeletal disorders: a review of epidemiological findings. Stockholm: National Institute for Working Life; 1997.

3. Bergqvist U, Wolgast E, Nilsson B, Voss M. Musculoskeletal disorders among visual display terminal workers: individual, ergonomic, and work organizational factors. Ergonomics 1995;38:763-76.

4. Bongers PM, Kremer AM, ter Laak J. Are psychosocial factors, risk factors for symptoms and signs of the shoulder, elbow, or hand/wrist?: a review of the epidemiological literature. Am J Ind Med 2002;41(5):315-42.

5. National Research Council and the Institute of Medicine. Musculoskeletal disorders and the workplace: low back and upper extremities. Washington (DC): National Academy Press; 2001.

6. Halpern CA, Davis PJ. An evaluation of work station adjustment and musculoskeletal discomfort. In: Proceedings of the 37th Annual Meeting of the Human Factors Society; 1993. Seattle (WA): Human Factors and Ergonomics Society; 1993. p 817-21.

7. Amell TK, Kumar S. Cumulative trauma disorders and keyboarding work. Int J Ind Ergon 1999;25:69-78.

8. Visser B, De Korte E, Van der Kraan I, Kuijer P. The effect of arm and wrist supports on the load of the upper extremity during VDU work. Clin Biomech 2000;15 Suppl 1:34-8.

9. Winkel J, Oxenburgh M. Towards optimizing physical activity in VDT/office work. In: Sauter S, Dainoff M, Smith M, editors. Promoting health and productivity in the computerized office. London: Taylor and Francis; 1990. p 94-118.

10. Galinsky TL, Swanson NG, Sauter SL, Hurrell JJ, Schleifer LM. A field study of supplementary rest breaks for data entry operators. Ergonomics 2000;43:622-38.

11. Ferreira M, Souza Conceição M de, Saldiva PHN. Work organization is significantly associated with upper extremities musculoskeletal disorders among employees engaged in interactive computer-telephone tasks of an international bank subsidiary in São Paulo, Brazil. Am J Ind Med 1997;31:468 73.

12. Thé KH, M Douwes, PM Bongers. Kort en vaak pauzeren ter preventie van RSI. [taking short and frequent breaks to prevent RSI]. Arbeidsgezondheidszorg en Ergonomie 1999;2:96-73.

13. Thompson DA. Effect of exercise breaks on musculoskeletal strain among data-entry workers: a case study. In: Sauter SL, Dainoff M, Smith M, editors. Promoting health and productivity in the computerized office: models of successful ergonomic interventions. London: Taylor \& Francis; 1990. p 118-27.

14. McLean L, Tingley M, Scott RN, Richards J. Computer terminal work and the benefit of microbreaks. Appl Ergon 2001;32:225-37.

15. Sundelin G, Hagberg M. The effects of different pause types on neck and shoulder EMG-activity during VDU work. Ergonomics 1989;32:527-37.

16. Henning RA, Alteras-Webb SM, Jacques P, Kissel GV, Sullivan A. Frequent short breaks during computer work: the effects on productivity and well-being in a field study. In: Luczak H, Çakir A, Çakir G, editors. Proceedings of work 
with display units 92. Amsterdam (etc): North-Holland, Elsevier Science Publishers BV; 1993;292-5.

17. Dababneh AJ, Swanson N, Shell RL. Impact of added rest breaks on the productivity and well being of workers. Ergonomics 2001;44(2):164-74.

18. Gezondheidsraad [Health Council of The Netherlands]. RSI. The Hague: Gezondheidsraad; 2000.

19. Arbeidsinspectie [Labour Inspectorate]. Werken met beeldschermen [Work with visual display units]. The Hague: SDU; 1993. Publication P184.
20. Karasek R. Job content instrument users guide: revision 1.1 Los Angeles (CA): Department of Industrial and Systems Engineering, University of Southern California; 1985.

21. Haberman SJ. Analysis of qualitative data; vol 1 (introductory topics). New York (etc): Academic Press; 1978.

22. Aiken LS, West SG. Multiple regression: testing and interpreting interactions. London: Sage Publications; 1991.

Received for publication: 12 June 2002 